\title{
Outcomes of a Life Skills Intervention for Homeless Adults with Mental Illness
}

\author{
Christine A. Helfrich · Louis F. Fogg
}

Published online: 1 June 2007

(C) Springer Science+Business Media, LLC 2007

\begin{abstract}
A manualized life skills intervention based on empowerment theory and situated learning was tested on 51 homeless adults with mental illness living in emergency or single room occupancy housing. The intervention improved skills in food, money, room, and self-care management and safe community participation. Participation included baseline measures with intervention post-tests and three and six month follow up measures. Comparisons were made to examine effectiveness between modules. There were significant improvements over time for the room and self-care and safe community participation modules, whereas the other modules did not reach statistical significance. The results suggest that through intervention this population may develop and retain the life skills needed to maintain residential stability.
\end{abstract}

Keywords Life skills $\cdot$ Mental illness $\cdot$ Homelessness $\cdot$ Empowerment theory · Situated learning

\section{Introduction}

Adults with mental illness are at risk for becoming homeless and those who are homeless are more likely to remain so without intervention. Homeless individuals who experience mental illness spend more days homeless, rate their quality of life lower than those without mental illness, and have marked problems meeting subsistence needs (Sullivan et al. 2000). Homeless shelters have few resources for

C. A. Helfrich $(\square)$

Department of Occupational Therapy (M/C 811), College of Applied Health Sciences, University of Illinois at Chicago, 1919 W. Taylor Street, Chicago, IL 60612-7250, USA e-mail: helfrich@uic.edu

L. F. Fogg

Department of Psychology and Rush College of Nursing, Rush, Presbyterian - St. Luke's Medical Center, Rush University, Chicago, IL, USA 
individuals with mental illness. Psychosocial rehabilitation programs offer psychoeducational groups addressing community reintegration (Longo 2002), yet few programs for adults with mental illness teach independent living skills in a way that allows for practice, integration, retention, and generalization to occur.

This paper describes the outcomes of a life skills intervention designed to maintain residential stability and prevent subsequent homelessness for adults with mental illness living in supervised emergency housing or single room occupancy housing with case management. The study was conducted with an Emergency Housing Program (EHP) operated by an academic medical center psychiatry department that provides supervised and protected housing for 23 homeless adults with psychiatric disabilities experiencing an acute psychiatric episode. Over half have co-occurring substance use diagnoses. This program provides basic support, social services and transitional services with 24 hours, 7 day-a-week access to on-site staff. The average length of stay is three to four months. The Single Room Occupancy (SRO) site provides safe, affordable, supportive housing for 583 low-income adults, homeless adults, and those at risk of homelessness. Residents live in both subsidized (45\%) and unsubsidized (55\%) rooms with case management and supportive services available if they choose to access them.

Although programming at both sites includes mental health supportive services, social services, and transitional services, the life skills that are taught are broad in scope and presented in a general manner. The training is not individualized and does not provide for repetitive practice or ongoing coaching. Persons with cognitive limitations and homeless persons often require specialized care to acquire skills that support independent living. The intervention described in this paper aimed to improve skills in room and self care management, food management, money management, and safe community participation.

\section{Background}

\section{Overview}

Although psychiatric symptoms are often linked to homelessness, their relationship to functional impairment is often overlooked. Mental illness and homelessness create a cycle of functional impairment that results in an inability to achieve and retain the basic skills necessary for living independently. Functional impairments impact an individual's personal health, functioning, productivity in personal and vocational areas, and his/her ability to maintain social relationships (Goodman et al. 1991; Gorde et al. 2004; Sullivan et al. 2000). Individuals with mental illness often have difficulty maintaining stable housing and functioning independently in the community and may welcome support for daily activities such as budgeting, shopping, and cleaning, which improve their ability to manage their lives independently (Calysn et al. 2002; Schutt and Goldfinger 1996). Practical assistance and skill training enhance their ability to retain housing when it emphasizes areas such as being a responsible tenant and managing routine finances (Harp 1990; Sosin and Grossman 1991). 
Persons with mental illness encounter disability related limitations and other barriers when accessing housing services such as eligibility criteria, lack of transportation, inadequate resources, or cost (Gallop and Everett 2001). Barriers also include lack of culturally appropriate or problem-specific services, distrust or fear of the 'system,' geographic isolation, and poverty (Fisk and Frey 2002; Rowe et al. 2003). Mental health service referrals may only be made if there is a mental health crisis severe enough to require hospitalization (Drury 2003).

Though providing housing improves cognitive functioning (Seidman et al. 2003) and decreases rehospitalization (Rosenfield 1991), the acquisition of life skills may allow more individuals with psychiatric disabilities to live in the least restrictive environment of their choice. When educational and practical components are integrated into service programs for adults with mental illness who are homeless, the transition from institutional living to community living becomes an attainable goal (Kuno et al. 2000). Successful attempts to merge practical and direct supports for community living with the provision of temporary housing include programs that provide traditional case management in combination with life skills training (Calysn et al. 2002; Harp 1990; Morse et al. 1992; Wasylenki et al. 1993). These studies suggest that including life skills training within service agencies that address homelessness and mental illness results in greater success at assisting individuals to locate and maintain housing. The impact of adding services appears to be greatest for those individuals who are more severely impaired (Clark 2003). However, missing from all of these studies are detailed descriptions of the life skills programs that were offered and evidenced based outcomes that indicate their efficacy.

Proactive personalized interventions are also effective in helping homeless individuals with mental illness acquire and retain housing. Intensive case management and transitional housing often use this approach with significant results (Calysn et al. 2002; Harp 1990; Morse et al. 1992; Washington 2002). Programming factors are often based on psychiatric rehabilitation principles (Cnaan et al. 1992), including flexibility, advocacy, increased contact with staff, and an emphasis on teaching independent living skills. Providing practical skills interventions in small groups with consistent staff correlates with higher client satisfaction and greater success in maintaining housing (Calysn et al. 2002; Campanelli and Sacks 1992; Morse et al. 1992; Schutt and Goldfinger 1996; Shern et al. 2000; Wasylenki et al. 1993). These approaches have been included in programs designed and run by mental health consumers.

Theoretical Approaches to Intervention: Empowerment Theory and Situated Learning

Homeless consumers with psychiatric disabilities often feel alienated and disconnected from decision making about their health, living arrangements, and well being because of a mismatch between service provider recommendations and individual client goals (Fisk and Frey 2002; Tsemberis and Elfenbein 1999). Their lack of personal choice is linked to a decreased ability to maintain housing and meet their basic needs indicating that consumer involvement may be essential to provide successful and relevant services (Rowe et al. 2003; Tsemberis and Elfenbein 1999). 
There is a positive association between the ability of consumers to choose and control their services and their ability to function independently (Nelson et al. 1998).

An empowerment approach to research and service delivery is appropriate for oppressed groups such as homeless consumers of mental health services because of its emphasis on social action, individual justice, and active participation that give voice to research participants by actively involving them in the research design and giving them control over their involvement in the research process (Carling 1989; Tsemberis and Elfenbein 1999). Empowerment theory has been used successfully to develop programs for homeless consumers with psychiatric disabilities. Examples include a collaborative community development project among homeless tenants of a shelter and staff, an outreach program that employed homeless peers, a service project that trained homeless consumers for internships on service boards, and a Housing First program that offered increased consumer choice in service delivery (Fisk and Frey 2002; Greenwood 2005; Hoch 2000; Rowe et al. 2003). Despite the evidence to support collaboration between consumers and service providers, this population remains excluded from full involvement in service design, implementation and research (Gordon 2005; Minogue 2005; Rutter 2004). Reasons cited for this exclusion include consumers' dissatisfaction with the level of collaboration offered, difficulty working within existing organizational structures, logistical difficulties such as inadequate support, and service provider reluctance to share the decision-making process (Gordon 2005; Rutter 2004).

Social learning theory using a situated learning approach provides an intervention model where adult learners gain knowledge and skills by immersing themselves in a social learning community (Lave and Winger 1991). Situated learning places the client learner in contexts that reflect the real world with application to everyday situations (Stein 1998). The process follows a logical sequence of providing information, seeing the skill performed, and practicing the skill in a desired context (Nemec and McNamara 1992). Situated learning allows for (1) client choice and involvement to address those skills the individual wants and needs to learn, (2) didactic learning with modeling and practice in a context preferred by the individual, (3) evaluation of the skill in a specific context to identify barriers and supports needed to be successful in the skill, and 4) an individualized process that considers the individual's level of functioning. This approach has been used to teach social skills but not to implement or evaluate life skills interventions in relation to homeless persons with mental illness developing the skills to maintain housing (Liberman and Kopelowicz 2002; Liberman et al. 1986; Wallace 1998; Wong et al. 1988).

One study using these approaches with homeless persons with mental illness systematically described and evaluated a life skills intervention (employment, money management, or food/nutrition) with homeless youth, victims of domestic violence, and adults with mental illness (Helfrich et al. 2006a). About $62 \%$ of the study participants demonstrated clinical changes overall and the victims of domestic violence and adults with mental illness demonstrated statistically significant change. That study indicated that homeless individuals benefit from life skill interventions tailored to meet their needs. 
The purpose of this study was to use empowerment and social learning theories to evaluate a manualized life skills intervention to determine if adults with mental illness who were at risk for homelessness could (1) learn life skills in the areas of room and self care, food management, money management, and safe community participation through a group and individual intervention and (2) retain their knowledge and skills three to six months after completing the intervention. It was designed to determine if subgroups of the sample demonstrated differences in intervention outcomes based on demographic variables or functional status.

\section{Methods}

\section{Study Design}

This study used a longitudinal design with variable exposure to a novel life skills intervention. Participants completed an initial series of baseline evaluations and participated in 12 group and individual sessions with an occupational therapy interventionist from February 2005-April 2006. At the completion of the six-week module, a practical skills test (PST) was administered to assess knowledge attainment. Three and six months post intervention, participants' change and skill retention were reassessed for each module. Comparisons were made among the effectiveness of the four modules.

\section{Sample}

Participants were recruited from the EHP or SRO housing program located in a large multi-use building in a large Midwestern city through a combination of flyers posted in the building and attendance by the study interventionist at program meetings to explain the project and answer questions. In addition to these public methods of recruitment, the interventionist accepted individual referrals from staff and met individually with interested residents. Inclusion criteria required participants to have a documented mental illness and be living in one of the programs noted above. In addition, they had to identify a life skill need, be willing to engage in a 60 minutes group and a 60 minutes individual session each week, and be able to give informed consent. Additionally, all interested individuals were screened to verify their competence to give informed consent using the MacArthur Competence Assessment Tool for Clinical Research (Appelbaum 2001), which has excellent inter-rater reliability and construct validity (Dunn et al. 2006; Sturman 2005). Exclusion criteria were inability to understand English or tolerate a 60 minutes group. Grant funding provided participants with a $\$ 10$ grocery store gift certificate for each study phase (assessments, intervention, follow up). The University of Illinois and Northwestern University Institutional Review Boards approved all aspects of the study.

Participants enrolled in at least one of the four life skills intervention modules, which included six group and six individual sessions with an occupational therapist (Helfrich, 2006a, b, c, d). Most participants completed all four modules. EHP 
participants $(n=28)$ completed two group sessions per week for three weeks, and SRO participants $(n=23)$ completed one session weekly for six weeks to accommodate the variance in program demands for each group. The modules were completed in sequence and repeated two to four times during the study.

\section{Program Implementation}

All study participants completed an initial comprehensive evaluation that screened for cognitive, motor, and process ability, identified the individual's current life skills in room and self care management, food management, money management, and safe community participation, and evaluated his/her efficacy related to life skills, readiness to change, substance abuse history and severity of trauma experiences. The Global Assessment of Functioning (GAF) (American Psychiatric Association 2000) which demonstrates inter-rater reliability and validity (Startup et al. 2002) and a personal demographic interview were administered. Medical and psychiatric diagnoses were obtained from client records. The evaluation results identified the life skills areas that each individual needed or wanted to address. This information was used to collaborate with the participant to determine which life skills modules s/ he would attend. Because the intervention was based on an empowerment model, participants chose the modules they participated in, rather than being assigned by the interventionist. This assessment series and a practical skills test were repeated after the intervention and three and six months post intervention to measure change and skill retention.

Group sessions lasting 60 minutes were designed with a situated learning approach using psycho-educational materials and applied activities. Each module began with a topic overview and a discussion of how symptoms of mental illness interfere with the skills included in that module. Topics for the room and self care module included personal and public hygiene, health, clothing, home cleaning, and home organization. Food management included nutrition, food safety, budgeting, obtaining food, microwave cooking, and meal planning and preparation. Money Management included budgeting, shopping, advertising schemes and financial protection, banking and credit, and tools for money management. The Safe Community Participation module included community, public and home safety, health protection, physical safety and protection, and consumer and personal advocacy. At the end of each group session, participants completed a quiz to assess their knowledge and provide feedback on the intervention. The content of the individual sessions was chosen by each participant to allow for individualized application of the group content. Each session was goal directed, building upon the previous session. Individual sessions were held at a variety of locations including the program site, the individual's room, or in the community for tasks such as learning to use a food pantry, accessing public transportation, accessing banking services, or practicing community safety. If a participant missed a group session, the content was covered during an individual session. After each module, the practical skills test was administered to measure changes in knowledge and performance. 


\section{Data Collection Tools}

The practical skills tests (PST) were developed by the authors with input from individuals who made the transition into living independently in the community. These individuals were purposefully sampled (Krueger 1994) to represent various intervention sites. They helped to identify performance criteria and rubrics for evaluating that performance. The written PST was constructed to test practical knowledge that participants would have developed over the six-week module. Because the PST is in the process of development, several equivalent written versions were administered to participants over the course of the study; the majority used a 30-item version (Helfrich et al. 2006b). Raters were trained to score the tests and scoring guides were revised until a $90 \%$ interrater reliability was achieved to meet standards for test development (Frank-Stromborg 2004).

\section{Data Analyses}

Data were examined for assumptions of normality and to ensure that there were no far outlying values. Because these were interim analyses, no missing data imputations were performed. These will be conducted when data collection is complete.

Data analysis was conducted in two phases. The first examined the participants at one point in time (the postintervention assessment) in order to determine which measures predict differences between subjects. In this phase of the analysis, relatively stable characteristics such as age, sex, and psychiatric diagnosis were examined to see how well they predicted functional ability. These analyses calculated Pearson correlation coefficients for continuous predictors and conducted analysis of variance for discrete predictors.

The second phase of the analysis was concerned with more dynamic changes that took place over time. Because of the interim nature of these data, most of these analyses compared observations collected at the postintervention assessment, and then for the same person at the three-month follow-up. These analyses were conducted using a repeated measures analysis of variance where there were two repeated measures for the two time points.

\section{Results}

There were no significant differences between the two sites related to demographics or module outcomes; however, it must be noted that this was a small convenience sample. The demographics of the sample are described in Table 1. The sample presented with a wide variety of medical and psychiatric issues. Medically, $65 \%$ of the participants exhibited two to six different conditions with the majority experiencing cardiac, orthopedic, pulmonary, or endocrinological disorders. Only $8 \%$ did not identify any medical issue. Psychiatrically, the participants' primary diagnoses were mood disorders (50\%), psychotic disorders (26.1\%), anxiety disorders (6.5\%) and substance use disorders (2.2\%). An additional 10\% had co-occurring psychotic features and $43 \%$ had co-occurring substance use disorders. 
Table 1 Demographics of adults with mental illness at risk for homelessness

Participants $n=(\%), 51$

\begin{tabular}{|c|c|}
\hline \multicolumn{2}{|l|}{ Gender } \\
\hline Male, Female & $55 \%(28), 45 \%(23)$ \\
\hline Age & 26-66 years $(M=46$ years $)$ \\
\hline \multicolumn{2}{|l|}{ Ethnicity } \\
\hline White & $44 \%(22)$ \\
\hline Black & $36 \%(18)$ \\
\hline Hispanic & $3 \%(2)$ \\
\hline Multiracial & $5 \%(3)$ \\
\hline Other* & $12 \%(6)$ \\
\hline \multicolumn{2}{|l|}{ Relationship status } \\
\hline Single & $72 \%(37)$ \\
\hline Married & $8 \%(4)$ \\
\hline Dating & $8 \%(4)$ \\
\hline Life partner & $11 \%(6)$ \\
\hline \multicolumn{2}{|l|}{ Highest educational level completed } \\
\hline Some high school & $16 \%(8)$ \\
\hline High school degree or equivalency & $24 \%(12)$ \\
\hline Some college & $41 \%(21)$ \\
\hline Graduated college & $18 \%(9)$ \\
\hline Vocational training & $26 \%(13)$ \\
\hline Income & $\$ 0-\$ 12,000(M=\$ 5,822)$ \\
\hline Without entitlements, with entitlements & $\$ 0-\$ 2,000(n=15), \$ 6,000-\$ 12,000(n=34)$ \\
\hline Income Sources & SSI, SSDI, Employment, Other \\
\hline \multicolumn{2}{|l|}{ Employment status } \\
\hline Unemployed & $94 \%(48)$ \\
\hline Work part time, Work full time & $4 \%(2), 2 \%(1)$ \\
\hline
\end{tabular}

* Participants refused to categorize themselves into predefined categories

For the $84 \%$ who identified as being homeless in the past, the duration ranged from 2 to 4,380 days (Median = 214 days). The 16\% who stated they had not been homeless in the past included individuals who were discharged from a psychiatric hospital directly to the emergency housing program and individuals who lived in cars or abandoned buildings, but never actually spent a night sleeping on the streets. About $90 \%$ of the sample had lived alone for 3 to 480 months (40 years) $(M=186$ months, $S D=129)$ prior to being in the study. This large range was fairly evenly spaced with no extreme outliers to skew the mean. For the $42 \%$ who had been evicted at least once from independent living arrangements, the multiple reasons included non-payment of rent (83.3.\%), landlord dispute (16.7\%), broke rules of section 8 housing $(8.3 \%)$, kicked out by roommates $(8.3 \%)$, evicted by city $(8.3 \%)$, and unsure of reason $(8.3 \%)$. 


\section{Intervention Outcomes}

Table 2 indicates the mean score for the practical skills tests completed at the end of each module for the entire sample and the mean scores of those individuals who completed follow up tests three months later. Two-tailed Pearson correlations indicate that the Room and Self Care and Safe Community Participation tests $(n=15)$ are significantly correlated $(r=.608)$ at the $P=0.05$ level at the postintervention administration. The other practical skills tests are not correlated.

Analyses of variance (ANOVA) were conducted with the demographic variables of gender, race, age, and educational level. There were no significant differences based on gender or race. Age was negatively correlated to performance on the Food $(r=-0.0433, P=0.034)$ and Money Management $(r=-0.413, P=0.032)$ postintervention tests whereas educational level trended toward a positive correlation on the Food $(r=0.345, P=0.099)$ and Money Management $(r=0.319$, $P=0.105)$ post module tests. The correlations between age and education may reflect that the younger participants in the study have higher levels of education.

A one-way ANOVA between psychiatric diagnosis and each postintervention PST did not indicate any significant differences. However, a simple repeated measures one-way ANOVA across the four PST measures at posttest indicated significant differences in the percent correct on the four forms of the PST $F(3$, $7)=5.86, P=.025$. The highest percent correct was for Room and Self Care (86.79\%) and the lowest was for Money Management (66.08\%). Tukey's HSD posthoc tests showed these two to be significantly different from each other and also from the two intermediate measures Food Management (76.20\%) and Safe Community Participation (77.63\%) (Fig. 1). There were significant differences between the postintervention assessment and the three and six month follow-ups for the Room and Self Care and Safe Community Participation modules in that participants improved over time. This did not occur with the Money Management or Food Management modules.

Table 2 Practical skills tests (PST) scores post module and 3-month follow up

\begin{tabular}{|c|c|c|c|c|c|}
\hline & $\begin{array}{l}\text { Post module } \\
\text { mean }(\mathrm{SD}, N)\end{array}$ & $\begin{array}{l}\text { Post } \\
\text { module } \\
\text { range }\end{array}$ & $\begin{array}{l}\text { 3-Month } \\
\text { follow up } \\
\text { mean }(\mathrm{SD}, N)\end{array}$ & $\begin{array}{l}\text { 3-Month } \\
\text { follow up } \\
\text { range }\end{array}$ & $\begin{array}{l}\text { Repeated } \\
\text { measures } \\
F \text {-ratios } \\
F(\text { df } 1, \text { df } 2, P)\end{array}$ \\
\hline $\begin{array}{l}\text { Food } \\
\text { management }\end{array}$ & $\begin{array}{l}68.12 \% \\
\quad(17.66 \%, 24)\end{array}$ & $29.73-94.26 \%$ & $\begin{array}{l}79.94 \% \\
\quad(12.55 \%, 15)\end{array}$ & $44.93-93.92 \%$ & $\begin{array}{r}4.75(1,13, \\
P=.048)\end{array}$ \\
\hline $\begin{array}{l}\text { Money } \\
\text { management }\end{array}$ & $\begin{array}{l}65.12 \% \\
\quad(20.46 \%, 27)\end{array}$ & $32.40-96.67 \%$ & $\begin{array}{l}64.96 \% \\
\quad(15.71 \%, 19)\end{array}$ & $40.00-91.89 \%$ & $\begin{array}{r}3.37(1,13, \\
P=.089)\end{array}$ \\
\hline $\begin{array}{l}\text { Room and self } \\
\quad \text { care }\end{array}$ & $\begin{array}{l}81.11 \% \\
\quad(13.97 \%, 30)\end{array}$ & $68.60-100.00 \%$ & $\begin{array}{l}87.15 \% \\
\quad(8.61 \%, 12)\end{array}$ & $81.40-100.00 \%$ & $\begin{array}{r}2.43(1,10, \\
P=.150)\end{array}$ \\
\hline $\begin{array}{l}\text { Safe community } \\
\text { participation }\end{array}$ & $\begin{array}{l}69.31 \% \\
\quad(22.02 \%, 20)\end{array}$ & $8.75-97.50 \%$ & $\begin{array}{l}77.14 \% \\
\quad(19.02 \%, 14)\end{array}$ & $43.75-100.00 \%$ & $\begin{array}{r}3.95(1,12, \\
P=.070)\end{array}$ \\
\hline
\end{tabular}

* 6-Month follow up data was not included due to small sample size 


\section{Discussion}

The intervention reported on in this paper is an important contribution to the field of homelessness prevention services. Life skills are taught in a variety of ways in many programs, but this is the first study to our knowledge that has systematically studied and evaluated a manualized intervention program. It is vital that we understand how improved life skills can stabilize people with mental illness and allow them to function more independently in the community and improve their ability to maintain housing.

Although these study results are preliminary, the participants in this study demonstrated improvement over time, after the intervention was completed, on the PST. The Room and Self Care Module improved the most, followed by Safe Community Participation. These modules address the skills that this population is least likely to have successfully developed and thus represent the most novel of the four modules. Food and money management are skills that can be completed by

Fig. 1 Room and self care and safe community participation modules performance over time (a) Room and Self Care Module PST (b) Safe Community Participation Module PST
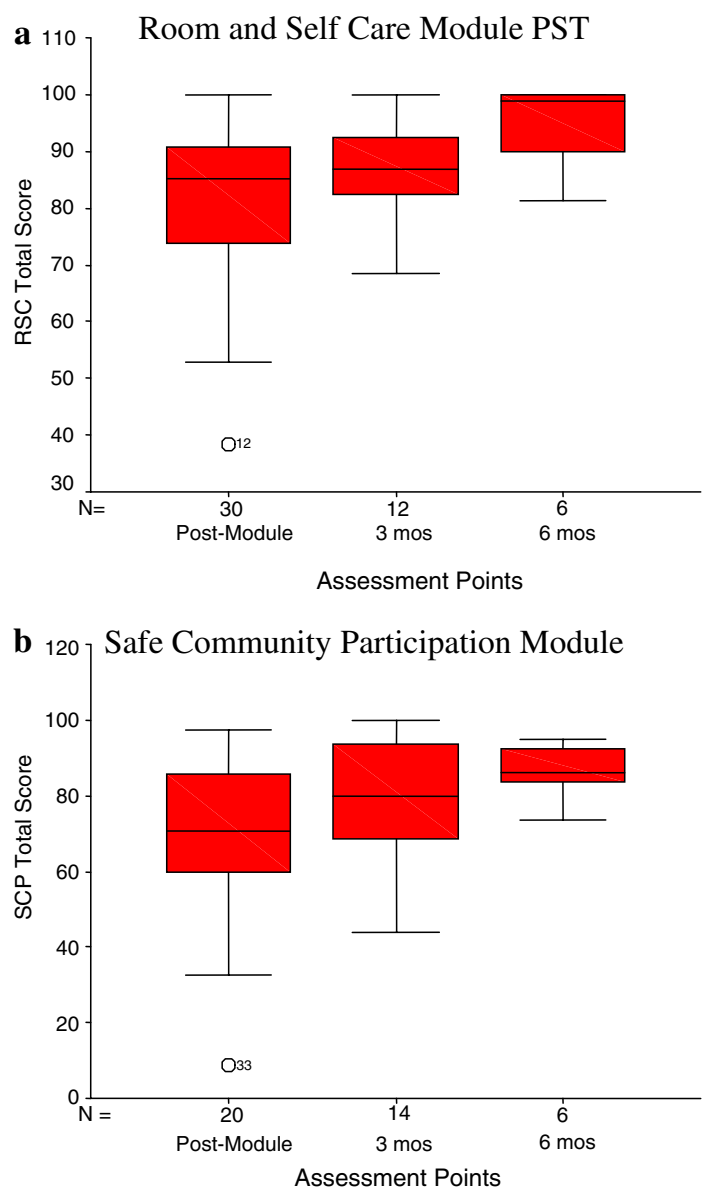
others if one chooses by not eating home cooked meals, attending soup kitchens, following the simplest money management techniques, or designating payees. This sustained improvement in skills was surprising and is probably best explained by the fact that learning and applying new skills and managing resources empowers the participants to become functionally competent (Zimmerman 2000).

Because being homeless is so demanding, and the presence of a mental illness increases this challenge, we expected the participants to be more medically unstable and to be less educated due to lack of opportunities to focus on education. They appear to reflect a broad range of backgrounds and life experiences, which may have some bearing on how they performed. Preliminary trends indicated that women may have performed better on the food module. Differences noted in education and age for the food and money management modules may be indicative of a relationship between age and education. The older participants in the study may be less educated than the younger participants. This age difference may be related to differences in academic educational achievements and/or greater access to information technology by the younger participants. At this midpoint of the study, the power of the data is not high enough to reach statistical conclusions about the extent to which multiple discrete demographic variables impacted performance. It is notable that despite this broad demographic range, the overall performance on the practical skills tests demonstrates such significant improvement.

Medically, the sample is very complicated. Most participants have multiple coexisting medical and psychiatric disorders. This population tends to have many concerns and fears related to health care resulting in avoidant behavior making them difficult to treat. Health issues in homeless populations also go undetected due to lack of access to health care (Substance Abuse and Mental Health Services Administration 2003); however, these individuals were living in a shelter operated by a medical center with access to a medical clinic. Despite this, many have not accessed health services and some have used their individual sessions to do so. It is very likely that for most participants, their health status would be worse if they did not have this access.

Psychiatric conditions were not related to PST performance as expected; however, this may result from the relatively low prevalence of psychotic disorders, which may result from the nature of the settings from which the clients were recruited. The absence of relationship between diagnoses and performance might also be explained by the theoretical framework and structure of the intervention. Empowerment theory stresses self-reliance and reliance on peer networks in solving problems (Rappaport 1994) in contrast to a traditional medical model approach which fosters dependence on experts. The intervention was individually designed, culturally relevant, and respectful of the strengths, concerns, and needs of clients so that individualized components could be implemented to maximize each client's strengths, address perceived obstacles, and facilitate successful experiences. This is a similar finding to another program effective in reducing homelessness that mixed the tenant population so that a diverse continuum of needs and skills were represented in the same location. As a result, tenants developed social networks, shared resources, and took collaborative actions to make their home a pleasant and safe place (Hoch 2000). Finally, it must be noted that the intervention in our study 
was delivered by an occupational therapist trained in social learning theory, which raises questions about how well the intervention will transfer for implementation by agency staff.

\section{Conclusion}

The early findings presented in this study indicate that the intervention assists homeless adults with mental illness to develop and retain life skills in the areas of room and self care, food management, money management, and safe community participation. Individuals are followed for six months after the modules and small groups of participants meet during the study as part of the empowerment evaluation process. Preliminary findings indicate participants are maintaining the skills acquired while in the study and using the materials provided in the modules after they are completed. The social learning theory, which guides the situated learning activities in the intervention, may be an important factor in this success. Participants describe using the manuals and workbooks as resource materials when they encounter difficulties adjusting to living independently, thus indicating the likelihood of skill retention and continued improvement.

Further research is needed to identify fully the power of these findings and to delineate factors that contribute to the success of this intervention. Further exploration may differentiate subgroups of the homeless population that perform differently in discrete ways. The modules need to be replicated in other settings to determine their efficacy and need for adaptation. Further research will need to evaluate the efficacy of the intervention approach and materials to improve residential stability and prevent further homelessness among persons with mental illness.

Acknowledgments This research was supported by Grant No. H133G040320 from the National Institute for Disability and Rehabilitation Research. The authors would like to acknowledge the support of the Lawson House YMCA and Northwestern Memorial Hospital.

\section{References}

American Psychiatric Association (2000). Diagnostic and statistical manual of mental disorders (4th ed.). Washington, DC: Author.

Appelbaum, T. (2001). MacArthur competence assessment tool for clinical research. Sarasota: Professional Resource Press.

Calysn, R. J., Morse, G. A., Klinkenberg, W. D., Yonker, R. D., \& Trusty, M. L. (2002). Moderators and mediators of client satisfaction in case management programs for clients with severe mental illness. Mental Health Services Research, 4(4), 267-275.

Campanelli, P. C., \& Sacks, J. Y. (1992). Integrating psychiatric rehabilitation within a community residence framework. Psychosocial Rehabilitation Journal, 16(1), 135-147.

Carling, P. J. (1989). Access to housing: Cornerstone of the American dream. Journal of Rehabilitation, July/August, 6-8.

Clark, C., \& Rich, A. R. (2003). Outcomes of homeless adults with mental illness in a housing program and in case management only. Psychiatric Services, 54(1), 78-83.

Cnaan, R. A., Blankertz, L., \& Saunders, M. (1992). Perceptions of consumers, practitioners, and experts regarding psychosocial rehabilitation principles. Psychosocial Rehabilitation Journal, 16(1), 95-114. 
Drury, L. J. (2003). Community care for people who are homeless and mentally ill. Journal of Health Care for the Poor and Underserved, 14(2), 194-207.

Dunn, L. B., Mowrangi, M. A., Palmer, B. W., Jeste, D. V., \& Saks, E. R. (2006). Assessing decisional capacity for clinical research or treatment: A review of instruments. American Journal of Psychiatry, 163, 1323-1334.

Fisk, D., \& Frey, J. (2002). Employing people with psychiatric disabilities to engage homeless individuals through supported socialization: The Buddies project. Psychiatric Rehabilitation Journal, 26(2), 191-196.

Frank-Stromborg, M., \& Olsen, S. J. (2004). Instruments for clinical healthcare research. Sudbury, Ontario: Jones and Bartlett Publishers, Inc.

Gallop, R., \& Everett, B. (2001). Recognizing the signs and symptoms. In B. Everett \& R. Gallop (Eds.), The link between childhood trauma \& mental illness: Effective interventions for mental health professionals (pp. 57-79). Thousand Oaks, CA: Sage Publications.

Goodman, L., Saxe, L., \& Harvey, M. (1991). Homelessness as psychological trauma: Broadening perspectives. American Psychologist, 46(11), 1219-1225.

Gorde, M., Helfrich, C. A., \& Finlayson, M. L. (2004). Trauma symptoms and life skill needs of domestic violence victims. Journal of Interpersonal Violence, 19(6), 691-708.

Gordon, S. (2005). The role of the consumer in the leadership and management of mental health services. Australasian Psychiatry, 13(4), 362-365.

Greenwood, R. M., Schaefer-McDaniel, N. J., Winkel, G., \& Tsemberis, S. J. (2005). Decreasing psychiatric symptoms by increasing choice in services for adults with histories of homelessness. American Journal of Community Psychology, 36(3/4), 223-238.

Harp, H. (1990). Independent living with support services: The goal and future for mental health consumers. Psychosocial Rehabilitation Journal, 13(4), 85-89.

Helfrich, C. (2006a). Food management: A life skills intervention. Chicago: University of Illinois at Chicago.

Helfrich, C. (2006b). Money management: A life skills intervention. Chicago: University of Illinois at Chicago.

Helfrich, C. (2006c). Room and self care: A life skills intervention. Chicago: University of Illinois at Chicago.

Helfrich, C. (2006d). Safe community participation: A life skills intervention. Chicago: University of Illinois at Chicago.

Helfrich, C., Aviles, A., Walens, D., Badiani, C., \& Sabol, P. (2006a). Life skills interventions with homeless people: Youth, domestic violence and mental illness. Homelessness in America: Perspectives, Characterizations and Considerations for Occupational Therapy, 20(3/4), 189-207.

Helfrich, C., Fogg, L., \& Levin, M. (2006b). Development and reliability of the practical skills tests. Chicago: University of Illinois at Chicago.

Hoch, C. (2000). Sheltering the homeless in the US: Social improvement and the continuum of care. Housing Studies, 15(6), 865-876.

Krueger, R. A. (1994). Focus groups: A practical guide for applied research (2nd ed.). Thousand Oaks, CA: Sage.

Kuno, E., Rothbard, A. B., Avery, J., \& Culhane, D. (2000). Homelessness among persons with serious mental illness in an enhanced community-based mental health system. Psychiatric Services, 51(8), 1012-1016.

Lave, J., \& Winger, E. (1991). Situated learning. New York, NY: Cambridge Press.

Liberman, R. P., \& Kopelowicz, A. (2002). Teaching persons with severe mental disabilities to be their own case managers. Psychiatric Services, 53(11), 1377-1379.

Liberman, R. P., Mueser, K. T., Wallace, C. J., Jacobs, H. E., Eckman, T., \& Massel, H. K. (1986). Training skills in the psychiatrically disabled: Learning coping and competence. Schizophrenia Bulletin, 12(4), 631-647.

Longo, D. A., Marsh-Williams, K., \& Tate, F. (2002). Psychosocial rehabilitation in a public psychiatric hospital. Psychiatric Quarterly, 73(3), 205-215.

Minogue, V., Boness, J., Brown, A., \& Girdlestone, J. (2005). The impact of service user involvement in research. The International Journal of Health Care Quality Assurance, 18(2), 103-112.

Morse, G. A., Calsyn, R. J., Allen, G., Tempelhoff, B., \& Smith, R. (1992). Experimental comparison of the effects of three treatment programs for homeless mentally ill people. Hospital and Community Psychiatry, 43(10), 1005-1010. 
Nelson, G., Walsh-Brown, R., \& Hall, G. B. (1998). Housing for psychiatric survivors: Values, policy, and research. Administration and Policy in Mental Health, 25(4), 455-462.

Nemec, P. B., \& McNamara, S. (1992). Direct skills teaching. Psychosocial Rehabilitation Journal, $16(1), 13-22$.

Rappaport, J. (1994). Empowerment as a guide to doing research: Diversity as a positive value. In E. J. Trickett, R. J. Watts, \& E. Birman (Eds.), Human diversity: Perspectives on people in context (pp. 404-423). San Francisco, CA: Jossey-Bass Inc.

Rosenfield, S. (1991). Homelessness and rehospitalization: The importance of housing for the chronic mentally ill. Journal of Community Psychology, 19(1), 60-69.

Rowe, M., Benedict, P., \& Falzer, P. (2003). Representation of the governed: Leadership building for people with behavioral health disorders who are homeless or were formally homeless. Psychiatric Rehabilitation Journal, 26(3), 240-248.

Rutter, D., Manley, C., Weaver, T., Crawford, M. J., \& Fulop, N. (2004). Patients or partners? Case studies of user involvement in the planning and delivery of adult mental health services in London. Social Science \& Medicine, 58(10), 1973-1984.

Schutt, R. K., \& Goldfinger, S. M. (1996). Housing preferences and perceptions of health and functioning among homeless mentally ill persons. Psychiatric Services, 47(4), 381-386.

Seidman, L. J., Schutt, R. K., Caplan, B., Tolomiczenko, G. S., Turner, W. M., \& Goldfinger, S. M. (2003). The effect of housing interventions on neuropsychological functioning among homeless persons with mental illness. Psychiatric Services, 54(6), 905-908.

Shern, D. L., Tsemberis, S., Anthony, W., Lovell, A. M., Richmond, L., Felton, C. J., et al. (2000). Serving street-dwelling individuals with psychiatric disabilities: Outcomes of a psychiatric rehabilitation clinical trial. American Journal of Public Health, 90(12), 1873-1878.

Sosin, M. R., \& Grossman, S. (1991). The mental health system and the etiology of homelessness: A comparison study. Journal of Community Psychology, 19, 337-350.

Startup, M., Jackson, M. C., \& Bendix, S. (2002). The concurrent validity of the Global Assessment of Functioning (GAF). British Journal of Clinical Psychology, 41(4), 417-422.

Stein D. J. (1998). Situated learning in adult education. Columbus, OH: ERIC Clearinghouse on Adult, Career, and Vocational Education.

Sturman, E. D. (2005). The capacity to consent to treatment and research: A review of standardized assessment tools. Clinical Psychology Review, 25, 954-974.

Substance Abuse and Mental Health Services Administration. (2003). Blueprint for change: Ending chronic homelessness for persons with serious mental illness and/or co-occurring substance abuse disorders. Rockville, MD: U.S. Department of Health \& Human Services.

Sullivan, G., Burnam, A., Koegel, P., \& Hollenberg, J. (2000). Quality of life of homeless persons with mental illness: Results from the course-of-homelessness study. Psychiatric Services, 51(9), 1135-1141.

Tsemberis, S., \& Elfenbein, C. (1999). A perspective on voluntary and involuntary outreach services for the homeless mentally ill. New Directions in Mental Health Service, 82, 9-19.

Wallace, C. J. (1998). Social skills training in psychiatric rehabilitation: Recent findings. International Review of Psychiatry, 10(1), 9-19.

Washington, T. A. (2002). The homeless need more than just a pillow, they need a pillar: An evaluation of a transitional housing program. Families in Society: The Journal of Contemporary Human Services, 83(2), 183-188.

Wasylenki, D. A., Goering, P. N., Lemire, D., Lindsey, S., \& Lancee, W. (1993). The Hostel Outreach Program: Assertive case management for homeless mentally ill persons. Hospital and Community Psychiatry, 44(9), 848-853.

Wong, S. E., Flanagan, S. G., Kuehnel, T. G., Liberman, R. P., Hunnicutt, R., \& Adams-Badgett, J. (1988). Training chronic mental patients to independently practice personal grooming skills. Hospital and Community Psychiatry, 39(8), 874-879.

Zimmerman, M. A. (2000). Empowerment theory: Psychological, organizational and community levels of analysis. In J. Rappaport \& E. Seidman (Eds.), Handbook of community psychology (pp. 43-64). New York: Kluwer Academic/Plenum Publishers. 